\title{
The Impact of Physic Activity and Sports into Bodily Health
}

\author{
Ardian Shingjergji \\ Elbasan University "Aleksandër Xhuvani", Faculty of Education Sciences. \\ ardianshingjergjigmail.com
}

Doi:10.5901/jesr.2014.v4n4p76

\begin{abstract}
The great economic and social changes have undoubtedly been reflected, among others, even into changing our lifestyle, bringing both positive effects as result of increases in people's wellbeing as well as negative effects suchlike the sedentary work, overweight, etc. The last effects also favor the emotional stress as well as other illnesses, including blood pressure or cancer, making us, once more, estimate our common efforts and time to apply a healthy lifestyle, among which the physical activity and sports continue to be important elements. Therefore, once again, this study intends to bring into attention the need to preserve and check bodily weight, by making use of the means and methods giving the desirable physical shape to our own body, as well as to emphasize the importance the physical activity and sports in improving bodily health. The facts and data from world experience, alongside comments and conclusions, which have been presented as lectures, may serve to all categories and ages of the society, especially to the students of the Department of the Physical Education and Sports, at the Faculty of the Education Sciences.
\end{abstract}

Keywords: lifestyle, overweight, physical activity, sports, bodily health.

\section{Introduction}

For many people, the way the somatotype has been defined has to do with the classification of the physical appearance. "What we are and are made of" goes beyond the first sight and what we see on the mirror. This makes us think that human body is made of a wide range of components, (suchlike bones, muscles, fat), whose quantitative mass determine the state of bodily health and its physical performance

Despite that fact that each one of us possesses certain knowledge about the persistence of the bodily fat, practical research methods intending to determine its value have been challenged, even nowadays, in terms of being developed properly to go deeper with their studies to this field. This assertion is true not only to the sportive medicine, the physiology of the physical exercises, epidemiology, and the growth and development domains but even to human biology, the nurture sciences and the physical activity and sports.

All the ready-made methods evaluating the composition of the human body are based in some conjectures and this is why the percentage of the bodily fat is only determined approximately.

This fact, alongside the discomfort information of the bodily fat percentage, should make the teacher so physical education, trainers or fitness centers managers to be more careful while presenting data about bodily composition to their pupils, students, sportsmen or fitness managers.

\section{Concepts and Evaluations for Determining Bodily Fat}

There are many ways to determine the mass of the bodily fat for an individual. One of the most important is the percentage of the bodily fat which has been considered as linked with the preservation of the body weight.

In an approximate value, there is a defined range within which can vary the percentage of an individual's bodily fat. Thus, if a sportsman has been evaluated the hydrostatic weight defining that to be $15 \%$ his bodily mass is fat, he should consider that the real percentage varies from $13.8-16.2 \%$.

The physically active people are estimated to have a lot less fat than inactive people. In the following tabs there are some results taken from the great number of surveys by Wilmore, presenting fat percentage in sportsmen and sportswomen exerting different sport activities: 


\begin{tabular}{lll} 
Sports & Males & Females \\
\hline Running & & \\
Swimming & $6.3-7.5$ & $15.2-19.2$ \\
Ski & $5.0-8.5$ & 26.3 \\
Gymnastics & 7.4 & -- \\
Volleyball & 4.6 & $9.6-23.8$ \\
Basketball &.-- & 25.3 \\
Football & 9.7 & $20.8-26.9$ \\
Tennis & 13.9 & -- \\
Ice Hokey & 15.2 & --- \\
Weightlifting & 15.1 & -- \\
Body building & 9.8 & - \\
Non-sportsman & 8.4 & 25.5
\end{tabular}

\subsection{The concept of the desirable body composition.}

Although it is not easy to have a clear perception regarding the concept of body composition, we will refer to the data from Table one, given by a panel of well-known experts. The data characterize individuals from the late adolescence age to the adult one.

\begin{tabular}{lcc}
\multicolumn{1}{c}{ Classification } & Males & Females \\
\hline \% of the necessary fat & $1-5 \%$ & $3-8 \%$ \\
Sportsmen & $5-13 \%$ & $12-22 \%$ \\
Optimal health & $10-25 \%$ & $18-30 \%$ \\
Optimal fitness & $12-18 \%$ & $16-25 \%$ \\
Allowed limit of obesity & $22-27 \%$ & $30-34 \%$ \\
\hline
\end{tabular}

Tab.1 The allowed percentage of fat for individuals of different categories ${ }^{1}$

\subsection{The concept of the desirable body weight.}

Understanding this concept is linked with the knowledge between desirable body weight and the allowed weight. Here we are not considering one sole value of the weight but one of its variants. By sticking with the up-mentioned table, we can use the desirable classification to determine a "reasonable" weight. A reasonable intention would be, for instance, the value of the "optimal fitness", namely, the determination of the body fat percentage in males to be $12-18 \%$.

Then, what would be the variation of the corresponding weight? In the following data are presented the necessary formulas to answer to this question:

1. Counting the fat weight: $\mathrm{FW}=\mathrm{BW} \times \mathrm{Ff}$

2. Counting the Fat Free Weight: FFW $=B W-F W$

3. Counting the desired weight target: FFW

TW $=$ ( 1 - Fx)

$\mathrm{FW}=$ Fat Weight $\mathrm{BW}=$ Body Weight $\mathrm{Ff}=$ Coefficient of the body weight $\%$

FFW $=$ Fat Free Weight TW $=$ Desired Weight Targets Fx $=$ Coefficient of the $\%$ of the body fat

\section{Controlling Body Weight}

Whenever we refer to controlling body weight the discussions focus on obesity, followed by the introduction of the necessary guidelines on how to maintain the desirable body weight and addressing issues to the sport and fitness.

Regarding obesity, it's worth to mention the fact that most of the people become as such (namely: obese), mainly

\footnotetext{
${ }_{1}^{1}$ Modified from a roundtable discussion. Data from Food and Nutrition, Board: Recommended Dietary Allowances, 7th ed. Washington, D.C. National Academy of Sciences, 1968. Modified from table 80, HathaWay and Ford, 1960, "Heights and Weights of Adults in the U.S.", Home Economics Research Report No.10.ARS, USDA.
} 
because of the lack of physical activity. This is the truth both for the adolescents and for the adults. To this regard, a study in California showed that $14 \%$ of the high school students (both males and females), were obese, as a consequence of the lack of the physical activity by since the elementary school and on.

Specialists and the specialized authorities to this field ascertain that the normal weight gained between $25-30$ years old should not be surpassed during the rest of one's life. The weight passing $15 \%$ to what has been referred to as normal is inclined to bring obesity, whereas $25 \%$ over the normal weight would truly be considered obesity.

Obesity is the main factor in triggering such illnesses as diabetes, hypertension and coronary and kidney sicknesses, liver and biomechanical disorders, (especially problems with the spine and the soles of the foot). As a consequence, life-expectancy is lower among the obese population.

\subsection{Children and obesity}

Children are another category of population being too much vulnerable toward obesity. This is because of the obvious changes occurring in the course of their growing up which are associated with weight gain. It is already well-known that the obese children of 10 years of age, risk becoming obese adults. Further labeling of these children as obese and recommendations to control their weight might have a negative effect since it is not always quite clear whether they experience a reverse effect in their general health.

It should be accepted as a fact that, studies accomplished so far about the issues regarding overweight in children have somewhat been limited, especially those dealing with the energy dispersion and macro-nutrition, as well into selecting the proper methods to measure and estimate the health indicators for this age-group. Specialists think that the overused methods so far should be abandoned, such as the practices of dividing human bodies into fat-free and fatty ones, and new methodologies should be embraced, the ones making possible for a more straightforward meaning regarding the changes happening into human muscles and bones. The most effective method to be used in children is the one defining the body-mass-index (BMI), since it reflects the real changes into the formation of the body and its further development.

A part of the issues regarding childhood obesity is linked with the differences persisting in regard to obese and elegant children's perceptions or approaches towards physical education and other school activities. Studies show that obese children react negatively toward physical activities taking longer in time and requiring exertion of force and react positively toward activities requiring flexibility and motoric coordination. The opposite occurs with elegant children.

\section{The Impact of the Physical Exercises and Sports into Improving Bodily Health}

Exertion of physical activities and sports is, undoubtedly, one of the crucial factors bearing undisputable values and effecting directly to the balance and preservation of the human bodily health. However, it is very important to make the proper choice of the physical and sport exercises effecting the energy systems of metabolism, the formation and the preservation of the muscular mass, the reduction of the fat mass, strengthening of articulations, ligaments and the preservation of the bones density.

We have selected four base exercises which can be classified as main physical activities which are: walking, jogging, aerobical dancing and ascending/descending stairs.

Walking and jogging can be considered as very suitable exercises of a great aerobical level which do not necessarily require the learning of other wonts and can be exercised via simple means.

Walking intensity can be determined basing on the fitness specific level, varying from 26 minutes per mile down to 12 minutes per mile.

Moreover, jogging is a natural activity activating more muscles than simple walking, leading to a faster weight loss. In everyday practice, these exercises can complement each-other satisfactorily.

Aerobic dancing is classified as a high aerobical level activity, too, effecting directly into improving the cardiorespiratory fitness and into the tonicization of the musculature.

Since the training sessions contain warming, stretching and friability exercises, the execution of movements provide both spiritual satisfaction and health improvements into organism.

Ascending/descending steps is another activity being proposed as a crucial exercise in our selection. They can be practiced in many variants such as using the step-machine or simply by ascending steps.

The four base exercises proposed above can as well be alternated through practicing one's preferred sports, making use of their aerobic contribution of metabolism, their easy access and the satisfaction they provide. Such sports can be football, basketball, volleyball, handball, cycling in nature, swimming, rafting etc. 


\subsection{The model of a training programme for the bodily weight preservation and control.}

In addition, by evaluating the time and attempts to have a healthy lifestyle we are presenting a model of training programme based on and proposed to and applied by well-known authors suchlike Bob Green (specialist of physical exercises having twenty years of work experience with people of different social strata and professions, including wellknown names such as Winfrey, O.)

The programme envisages some of the most efficient degrees to increase metabolism and lead to excessive weight loss by combining exercising with physical and sport activities and dieting.

1. Five to seven times a week aerobic training, (walking, walking, -jogging, aerobic running, aerobic dancing, ascending/descending steps, swimming, rafting, strechting, etc.), especially in the morning.

2. Training in the "area", meaning exerting with proper intensity, (70 - 80\% of the heart maximal rhythm), to burn the necessary calories with the proper rhythm to bring the increase in metabolism.

3. Maintaining each training session $20-60$ minute long.

4. Balanced diet, using foodstuffs containing fat with low caloric values, based on the nutrition guideline pyramid.

5. Limitation or elimination of the alcoholic drinks.

6. Eating fruit at least twice a day three rations of vegetables.

7. Drinking $6-8$ glasses of water a day.

8. By promoting your day-to-day commitment for a healthy life.

\section{Conclusions}

Our common efforts, the efforts made by the specialists of the Physical Education and Sports as well as those of the society as a whole, should be directed towards further improvements of the bodily health, by promoting an active lifestyle keeping bodily weight under control as well as preserving a certain percentage of bodily fat level.

Getting aware of the negative effects the overweight causes to the bodily health, makes us evaluate once more the role of the physical and sports activities as contributors to the further improvements of the energetic systems of metabolism, the increase and preservation of the muscular mass, reduction of the fat mass, strengthening of articulations, ligaments as well as the improvements of human organism in general.

\section{References}

Atha, J., (1984). "Strengthing muscle". Exercise and Sport Sciences reviews.

Ajan, T., Boroga, I. (1988). "Weightlifting Fitness for all Sports". Budapest.

Canaj, P., Kapedani, K. (2002). "Sportive Hygiene”, f.163-166, 169-179, 181-187,194-205, 205-209, 250-252, $261-264$.

Foss, M. L., Steven, C., Keteyian, J., Ford, H. (1998). "Physiological Basis for Exercices and Sport". Heart \& Vascular Institute. Sixth edition, f. 440-441, 446-447, 459-461.

Greene, B., Winfrey, O. "Ophra's commitment for a better body and life " translated from the original by Jorgoni, A., f. 58-61, 76-81, 83205

Isaac, L., (2003). "Variables of Strength Training". A.W.F.

Mathews, D., Fox, E. (1976). "The Physiological Basis of Physical Education and Athletics".

Kraemer, W., Gomez, A. (2001). "Establishing a solid Fitness Base). S. C.

Zatsiorskij, V. (1995). "Science and Practice of Training". H. K 